\title{
Critical Infrastructure Monitoring with Global Navigation Satellite Systems
}

\author{
Jean-Philippe Montillet ${ }^{1}$; Walter M. Szeliga ${ }^{2}$; Timothy I. Melbourne ${ }^{3}$; Rex M. Flake ${ }^{4}$; and Gavin Schrock ${ }^{5}$
}

\begin{abstract}
This paper documents measured deformation within four global positioning system (GPS) networks deployed on critical, heavyengineered infrastructure in real time over a combined 5-year period. The first is an $\sim 2-\mathrm{km}$, four-lane floating freeway that deforms daily in response to temperature and traffic loads and seasonal lake-level variation. The second is a 6-lane elevated freeway $\sim 1 \mathrm{~km}$ in length that has subsided unevenly and discontinuously since it was damaged by the $2001\left(\mathrm{M}_{\mathrm{W}} 6.8\right)$ Nisqually earthquake. Two additional structures comprise 300-m-long, earth-filled dams forming major reservoirs (Howard A. Hanson and Tolt dams). Real-time kinematic processing of high rate (1s or 5-s epochs) GPS observations over short baselines $(0.1$ to $\sim 1 \mathrm{~km})$ permits continuous deformation monitoring at centimeter-level accuracy, whereas long-term deformation was measured at subcentimeter accuracy through postprocessing of 24-h observations. The floating freeway showed $60 \mathrm{~cm}$ of annual vertical displacement and a 1.4- $\pm 0.4-\mathrm{cm}$ short-period oscillation that correlates with traffic and temperature but no response to bridge-perpendicular winds gusting to $74 \mathrm{~km} / \mathrm{h}$ (40 knots). Along the elevated freeway, 4-7 mm/year of lateral displacement and $4.3 \pm 14 \mathrm{~mm} /$ year of subsidence is observed. At Howard A. Hanson Dam, daily measurements show a slow response at the southernmost portion of the dam to the filling with water of a 30-m-deep pit excavated adjacent to the dam. The fourth structure, Tolt Dam, is stable but shows a vertical response to reservoir level and appears to isolate its GPS receivers from a well-documented regional hydrological signal. DOI: 10.1061/(ASCE)SU.1943-5428.0000181. (C) 2016 American Society of Civil Engineers.
\end{abstract}

Author keywords: Global navigation satellite system (GNSS); Global positioning system (GPS); Real-time kinematic; Carrier-phase signal; Bridge deformation; Engineering safety; Double differencing.

\section{Introduction}

Global Navigation Satellite Systems (GNSS), of which the United States' global positioning system (GPS) was first to be fully deployed, have revolutionized surveying and positioning by enabling subcentimeter-level precision globally wherever sufficient sky view enables uninterrupted carrier-phase tracking. It has become a ubiquitous technology that underpins most aspects of precise timing and either relative or absolute positioning, ranging from short-aperture commercial land surveys made relative to local reference marks to measuring broad-scale crustal deformation with network positioning over baselines of $5,000 \mathrm{~km}$ or higher (Blewitt 1993).

\footnotetext{
${ }^{1}$ Research Fellow, Pacific Northwest Geodetic Array Laboratory, Central Washington Univ., Ellensburg, WA 98926 (corresponding author). E-mail: montilletj@cwu.edu

${ }^{2}$ Assistant Professor, Pacific Northwest Geodetic Array Laboratory, Central Washington Univ., Ellensburg, WA 98926. E-mail: walter@ geology.cwu.edu

${ }^{3}$ Professor and Director, Pacific Northwest Geodetic Array Laboratory, Central Washington Univ., Ellensburg, WA 98926. E-mail: tim@geology .cwu.edu

${ }^{4}$ Engineering Geologist, Pacific Northwest Geodetic Array Laboratory, Central Washington Univ., Ellensburg, WA 98926. E-mail: rex@geology .cwu.edu

${ }^{5}$ Land Surveyor, Engineering \& Technical Services Division, Seattle Public Utilities, Seattle, WA 98124. E-mail: gavin.schrock@ seattle.gov

Note. This manuscript was submitted on August 6, 2015; approved on December 23, 2015; published online on February 26, 2016. Discussion period open until July 26, 2016; separate discussions must be submitted for individual papers. This paper is part of the Journal of Surveying Engineering, (C) ASCE, ISSN 0733-9453.
}

Previous studies have shown the utility of using continuous GPS for the monitoring of dams and bridges using postprocessed GPS, but in real time, its use as a stand-alone system or as an enhancement to traditional measurement and monitoring techniques is useful for both surveying and critical infrastructure monitoring for public safety. In dam measurements, Hudnut and Behr (1998) described the thermal expansion of Pacoima Dam near Los Angeles, California, whereas Stewart and Tsakiri (2001) emphasized the limitations of traditional surveying techniques and proposed a GPS methodology to monitor dams. Rutledge et al. (2006) studied the difference in accuracy between the measurements from a real-time kinematic (RTK) system and a plumb line at Libby Dam (in Montana) and found excellent agreement between the two systems. Psimoulis and Stiros (2012) assessed the capability and accuracy between GPS and robotic total station in the determination of oscillations of major structures, whereas Bond et al. (2011) used six GPS stations and various sensors, including inverted pendulums, strain gauges, crack meters, and borehole extensometers, to monitor continuously the Mactaquac Dam (New Brunswick, Canada).

For monitoring bridges, Hyzak et al. (1997) was one of the first studies to discuss the application of GPS. Roberts et al. (2002) showed that millimeter-level bridge movements could be resolved using GPS integrated with other sensors, and subsequent studies from the same authors integrated RTK GPS and accelerometer measurements to estimate millimeter oscillations of the London Millennium Bridge due to the high volume of pedestrians (Roberts et al. 2004). Ogundipe et al. (2014) used RTK GPS to monitor relatively small deformations on a steel box girder viaduct bridge in the United Kingdom, and several other works recorded movements of tall structures caused by ground shaking from seismic waves (Çelebi et al. 1999) or strong wind loads (Guo and Ge 1997). Meng et al. (2004) monitored the deformations of several bridges around the United Kingdom and Australia using GPS augmented with 
pseudolites. Erdoğan and Gülal (2009) modeled the periodic signals in the time series of the longitudinal, lateral, and vertical movement of the Istanbul Bosphorus Bridge to monitor its structural response to wind speed, temperature change, and traffic load.

The aim of this paper is to document the precision of continuous GPS for both real-time deformation monitoring of critical infrastructure and, in postprocessing mode, to measure structural deformation caused by a wide variety of environmental stresses. Results are described from four multistation GPS deployments in Washington State specifically designed to measure deformation of critical civil infrastructure in real time over a combined 5-year period. The first is a floating freeway that deforms in response to daily variations of traffic and temperature and seasonal lake-level variation. The second is an elevated freeway traversing downtown Seattle, that was damaged by the $2001 \mathrm{M}_{\mathrm{W}} 6.8$ Nisqually earthquake beneath southern Puget Sound and has subsided unevenly and discontinuously since. Two additional structures comprise large, earth-filled dams forming major reservoirs that serve the greater metropolitan populations of Seattle and Tacoma, Washington, along the west slope of the North Cascade Mountains. The first was discovered to be leaking along its periphery and underwent major structural modification coincident with the excavation and refilling with water of a $30 \times 20 \mathrm{~m}, 30-\mathrm{m}$ deep pit adjacent to the dam that caused detectable deformation within the portion of the dam structures closest to excavation. The second dam is stable but is shown to respond to seasonal fluctuation in the water height of the pool level behind the dam. In the following sections either the real-time or postprocessed observation is discussed, depending on which contained signals of greatest interest, from the four GPS networks.

\section{Four Bridge and Dam GPS Deployments}

The four structural monitoring networks described here were all built either on functioning freeways that accommodate high volumes of traffic or major dams retaining large ( $>5 \mathrm{~km}$ in length) reservoirs at full or nearly full levels. Antenna monuments were fabricated of 15-gauge steel or stronger and specific to the requirements of each deployment, given their critical importance in providing submillimeter long-term stability. Examples of antenna mounts are shown as insets in Figs. 1-4, and are either deep drill-braced stainless steel tripods for dike and reference sites or fabricated stainless steel pillars, braces, or columns for on-dam sites. All monuments and radio telemetry systems were installed and serviced during access windows scheduled by operating agencies or by the application process to the relevant agency.

\section{Evergreen Point Floating Bridge on Lake Washington}

The Evergreen Point Floating Bridge (Fig. 1) is operated by the Washington State DOT (WSDOT) and carries over 100,000 cars per day across Lake Washington between the City of Seattle and its suburbs. The bridge's total length is approximately 4,750 $\mathrm{m}(15,580$ $\mathrm{ft})$, and its 2,310-m (7,580-ft) floating section is the longest existing floating bridge. The GPS station $520 \mathrm{~N}$ was deployed as part of a study in conjunction with WSDOT to continuously monitor bridge response in real time to wind, waves, and traffic loads as well as to schedule periodic cable adjustments between the bridge and its anchors. Position deviations in excess of several decimeters cause the bridge to be closed with serious impact on traffic and businesses (WSDOT 2008). For this bridge, RTK positioning was processed relative to a continuous operating reference station, SEAT, due to its closest proximity to the bridge (baseline $\sim 3 \mathrm{~km}$ ) and 20 years of continuous observations. On the bridge itself, station position is at the midspan of the floating section and was selected by WSDOT based on car traffic, antenna vulnerability, sky view, proximity to major scatterers, and power and telemetry sources.

\section{Alaskan Way Viaduct Elevated Freeway}

The Alaskan Way Viaduct (Fig. 2) is a double-level elevated freeway that carries an average of 110,000 vehicles per day along the

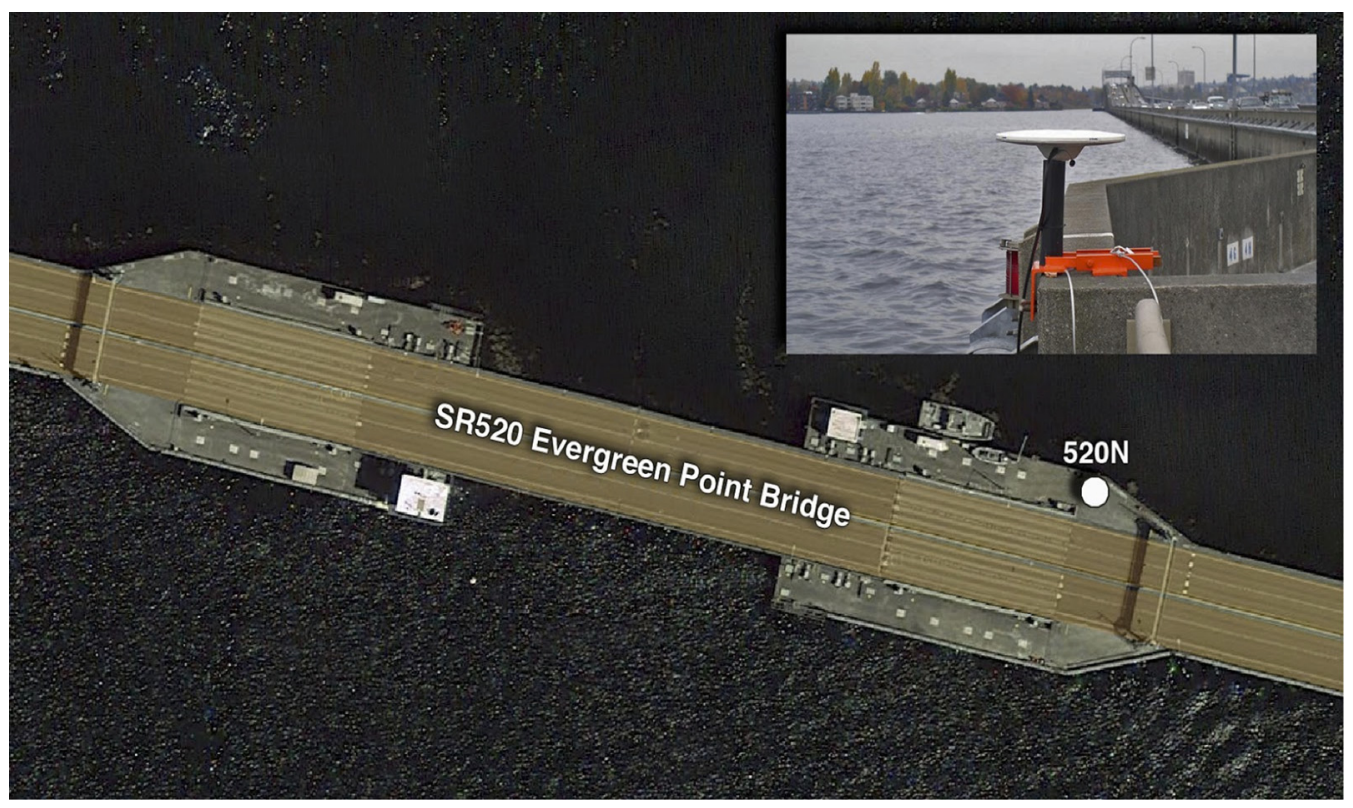

Fig. 1. (Color) Aerial view of the Evergreen Point Floating Bridge (SR520) across Lake Washington; GPS receiver 520N was installed midway across the 2.3-km floating section in late 2011 and operated through December 2012 (Imagery (C) 2015 Google, Landsat, USDA Farm Service Agency, Map data; inset image by Rex M. Flake) 


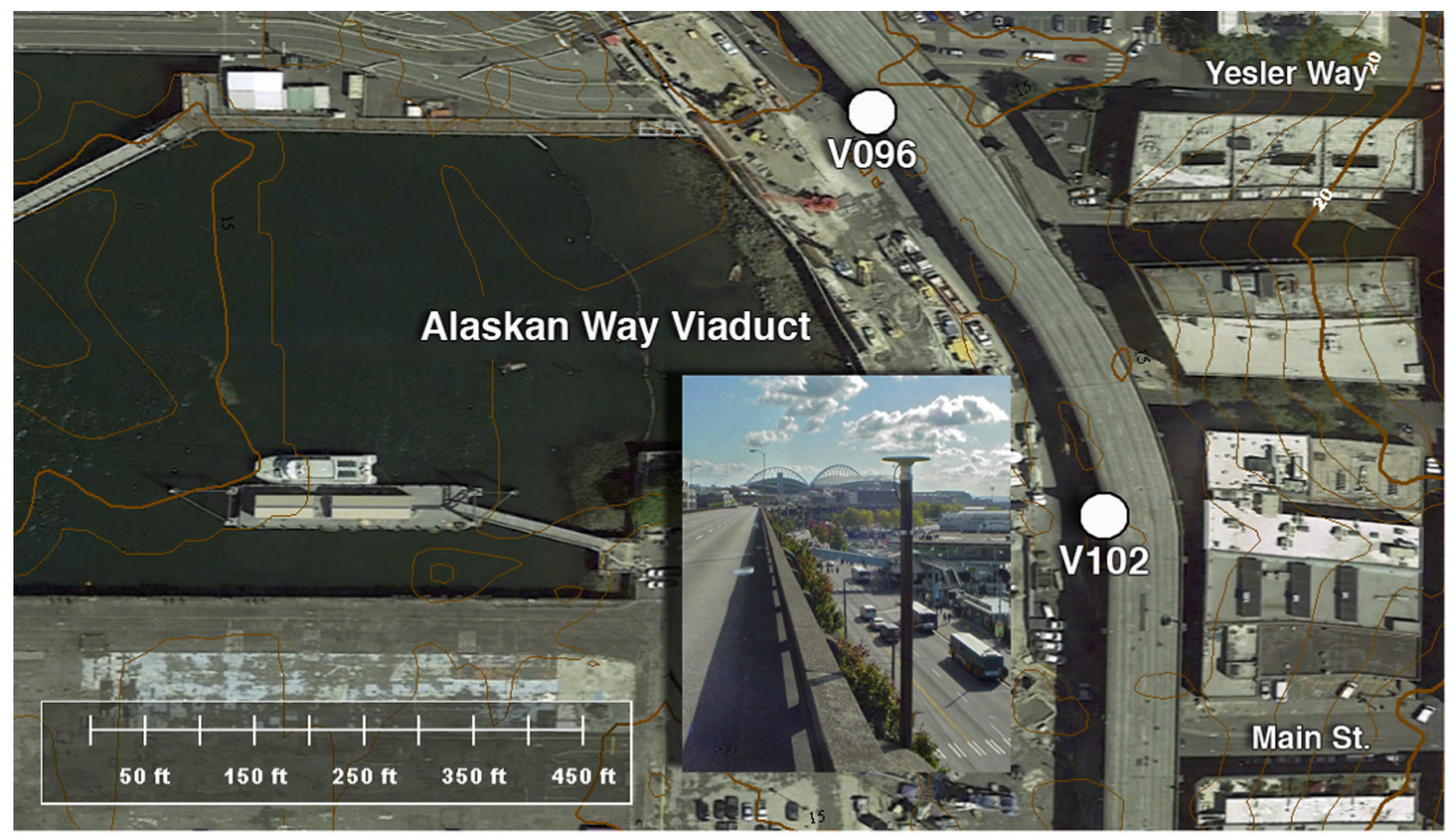

Fig. 2. (Color) Aerial view of the 6-lane elevated Alaskan Way Viaduct (SR99) through downtown Seattle. Antennas of GPS stations V096 and V102 were mounted on 4-m schedule-15 steel pipe to minimize disruption of sky view by freeway traffic (Imagery @ 2015 Google, Landsat, USDA Farm Service Agency, Map data; inset image by Rex M. Flake)

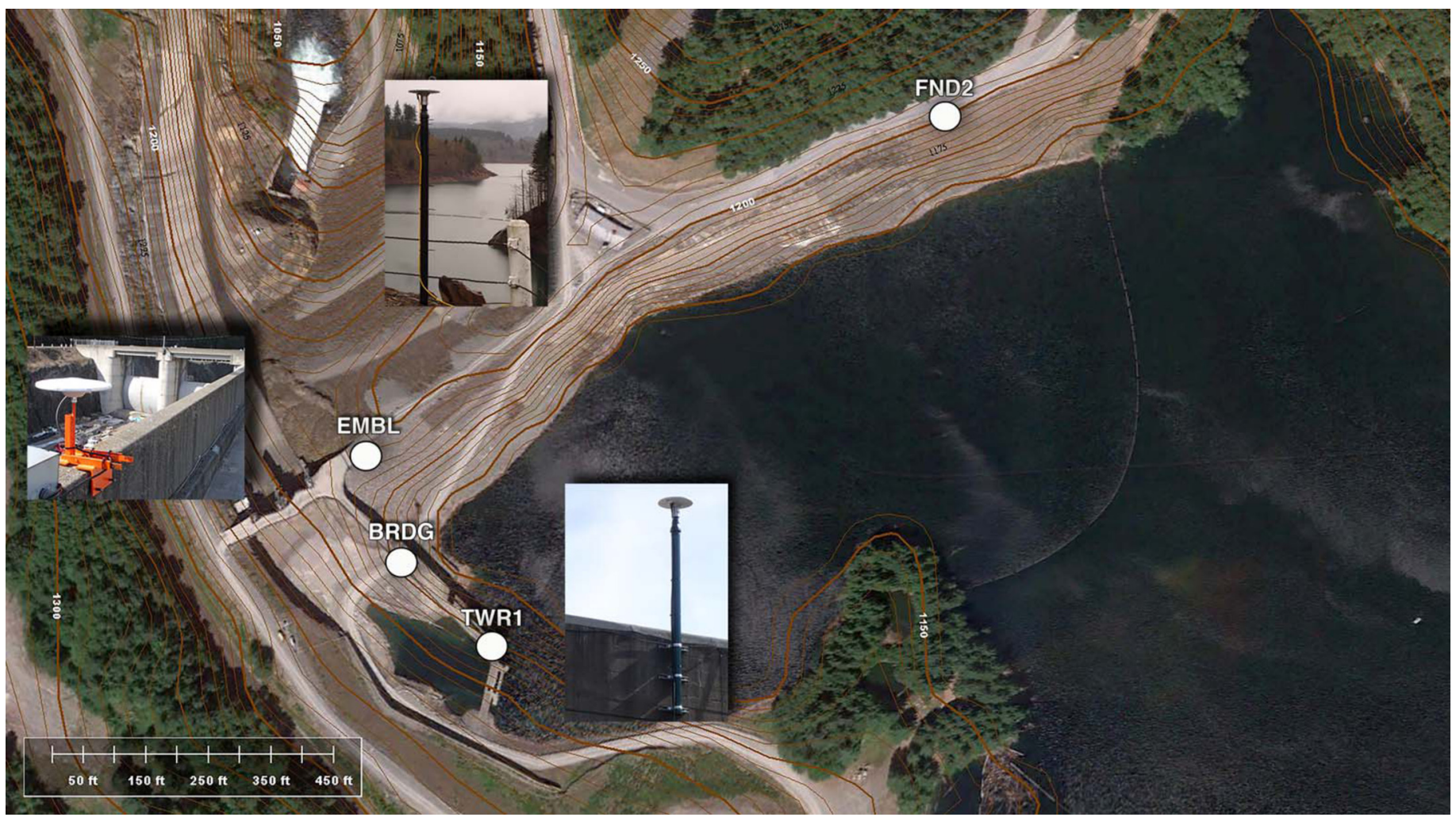

Fig. 3. (Color) Aerial view of the Howard A. Hanson Dam, located in the Green River west of Tacoma, Washington; only GPS stations whose data are shown in Fig. 8 are shown here; a total of 14 were installed (Imagery (C) 2015 Google, Landsat, USDA Farm Service Agency, Map data; inset images by Rex M. Flake) 


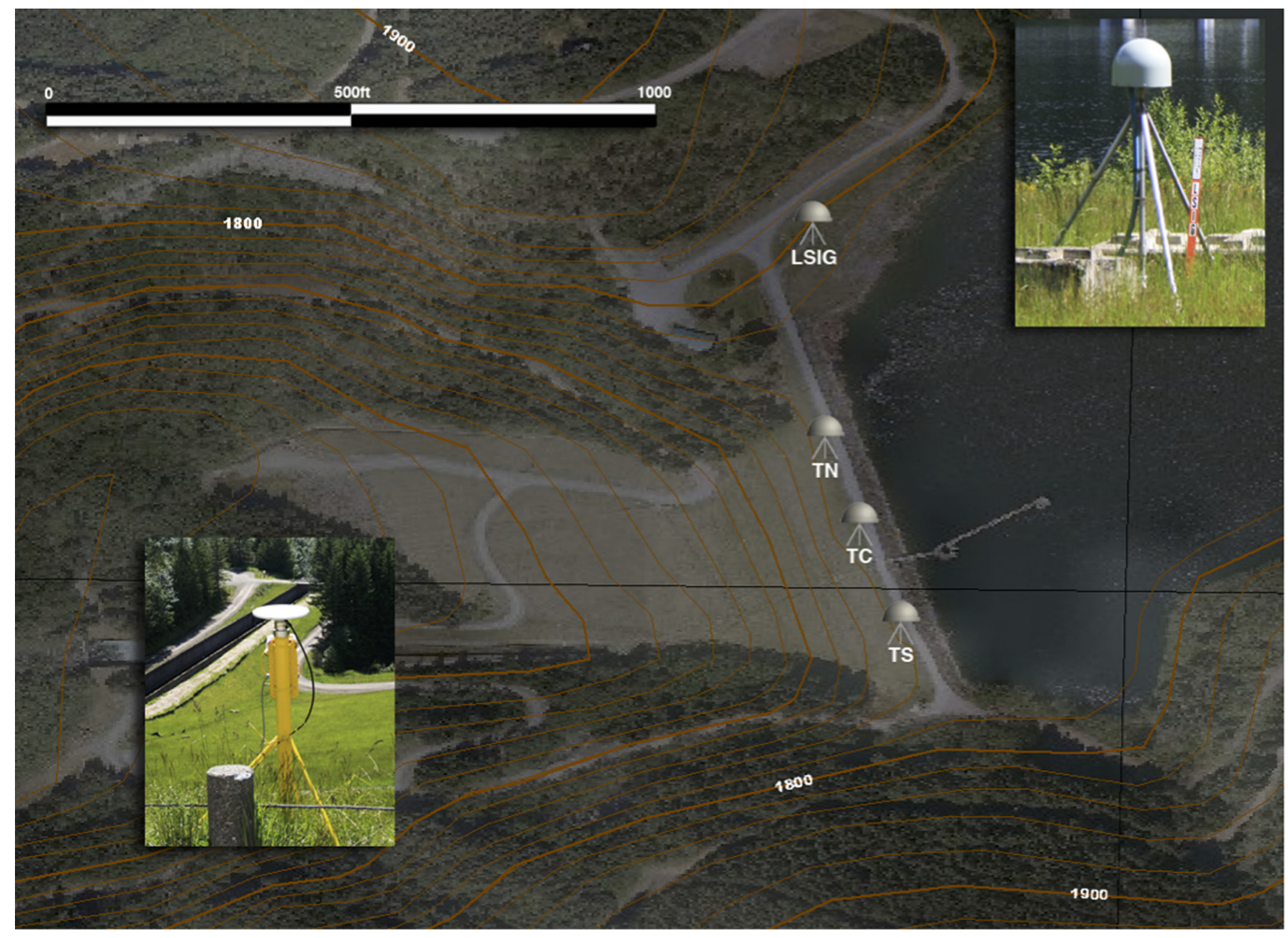

Fig. 4. (Color) Aerial view of the earth-filled Tolt Dam, with three GPS stations installed along its crest and a fourth one used as a reference station (LSIG) located on bedrock (Imagery @ 2015 Google, Landsat, USDA Farm Service Agency, Map data; inset images by Rex M. Flake)

Seattle waterfront. It was damaged by the 2001 magnitude 6.8 Nisqually earthquake, which produced cracking within the bridge and instigated emergency repairs. Two GPS receivers, V096 and V102, were installed to study subsidence and lateral deformation within the elevated viaduct. The locations of the two viaduct stations were selected with criteria similar to the 520 floating bridge but in the vicinity of the ongoing subsidence of the viaduct structure.

\section{Howard A. Hanson Dam}

Howard A. Hanson Dam is located on the Green River in Washington State above the City of Tacoma. It is operated by the U.S. Army Corps of Engineers (USACE). The dam is an earth-fill embankment structure $205 \mathrm{~m}(675 \mathrm{ft})$ wide at its crest and $290 \mathrm{~m}(960 \mathrm{ft})$ at its base, with a height of $70 \mathrm{~m}(235 \mathrm{ft})$. The dam structure contains a concrete spillway on its left side capable of discharging overflow at $3,000 \mathrm{~m}^{3} / \mathrm{s}\left(107,000 \mathrm{ft}^{3} / \mathrm{s}\right)$. In January $2009,38 \mathrm{~cm}$ ( $17 \mathrm{in}$.) of rainfall within $24 \mathrm{~h}$ peaked water inflows behind the reservoir at $860 \mathrm{~m}^{3} / \mathrm{s}\left(30,500 \mathrm{ft}^{3} / \mathrm{s}\right)$, raising the reservoir level to a record high of $362 \mathrm{~m}(1,189 \mathrm{ft})$ above sea level (maximum authorized storage level is $368 \mathrm{~m}$ ). Afterward, USACE discovered two depressions on the right abutment of the dam and increased water levels in groundwater. The USACE did not believe the dam was at immediate risk of failing, but by November 2009 an interim seepage barrier was constructed to reduce the chance of flooding downstream of the dam (USACE 2012). Fourteen GPS receivers were deployed throughout the dam and leaking abutment in early 2010 to monitor the response of the structure (see Fig. 3). After improvements to the dam's drainage were completed in October 2011, the GPS receivers were removed (USACE 2012).

\section{Tolt Dam and Reservoir}

Tolt Dam (see Fig. 4) is located on the South Fork Tolt River in Washington State, $25 \mathrm{~km}$ upstream from the City of Carnation, and provides $30 \%$ of total water use for the Seattle metropolitan area. It is also an earth-filled structure, $260 \mathrm{~m}$ wide at the crest, $140 \mathrm{~m}$ at its base, $60 \mathrm{~m}$ in height, and its $5.5-\mathrm{km}$ reservoir stores $71,500,000 \mathrm{~m}^{3}(57,900$ acre-ft) of water. The dam is operated by Seattle Public Utilities (SPU) and regulated by the U.S. Federal Energy Regulatory Commission (FERC). Three GPS receivers were installed on top of the structure to measure dam response to seismicity and variations of the pool level. The RTK positions were computed relative to the CORS station LSIG installed into bedrock just to the side of the Tolt Dam. The distances between GPS stations on top of the dam (TS, TN, and TC) are less than 
$100 \mathrm{~m}$, whereas the longest baseline (LSIG-TS) is $286 \mathrm{~m}$, and the resulting RTK position streams were monitored continuously and integrated into a dam failure warning system developed by SPU (2005).

\section{Real-Time Position Estimation and Postprocessing}

The RTK positions were estimated at a high rate (1- and 5-s epochs) using IGS ultra-rapid satellite orbit and clock corrections, which are half forward-predicted in time (Kouba and Héroux 2001) for use by operating agencies in determining bridge closures or reservoir lowering. Receivers deployed on structures were treated as kinematic rovers positioned over short baselines relative to nearby $(0.1$ to $\sim 2$ $\mathrm{km})$ reference stations using standard double-differencing TRACK software (Herring et al. 2010a) and a cutoff angle of $15^{\circ}$. For the floating bridge, positioning was performed relative to the permanent station SEAT located $3 \mathrm{~km}$ away, which has been in continuous operation since 1996. Because of the short baseline between the stations, the ionosphere delay is either not corrected or the observations are processed as a linear combination of the measurements on L1 and L2 (Seeber 2003). In RTK, positioning resolution is typically at the centimeter level (Seeber 2003).

In addition to RTK, postprocessed data were also recorded at each structure for daily (24-h) position averages to extract long-term deformation at millimeter amplitudes that are not detectable with RTK analysis. Daily processing methodology follows Szeliga et al. (2008), using final orbits and clocks from IGS. In this approach, daily GPS phase observations are used to estimate station position and atmospheric delay while holding IGS final orbits fixed to produce loosely constrained estimates of station positions and covariances using GAMIT v.10.50 (Herring et al. 2010a). These loosely constrained estimates of station positions and covariances are then used as input to $G L O B K$ v. 5.26 (Herring et al. 2010b) to estimate a consistent set of station coordinates and velocities. Regional measurements are tied to an external regional reference frame, rather than a single station, by simultaneously processing phase data from $\sim 20$ regional continuous stations, evenly distributed in azimuth relative to our network throughout the Pacific Northwest. The Vienna mapping function (VMF1) (Boehm et al. 2006) and zenith hydrostatic delay from the European Centre for Medium-Range Weather Forecast (ECMWF) numerical model are used (Boehm et al. 2006). The last step is the realization of the International Terrestrial Reference System (ITRF) 2008 reference frame by minimizing the difference between the positions and velocity of our 15 processed regional stations with those published in Altamimi et al. (2011). This results in a postfit network-wide error of $1.29 \mathrm{~mm}$ in position and $0.54 \mathrm{~mm} /$ year in velocity, which for daily positioning is shown to resolve structural deformation signals as small as $4 \mathrm{~mm}$ once annual signals are taken into account. The data available for this study span the period from 2011 to the end of 2014.

For postprocessed daily position estimates, identifying long-term transient motions requires a functional model to describe each putative transient. The model parameters are estimated using two methods. The first is standard least squares to solve for the coefficients of the model via inversion of its design matrix. However, long-term GPS position estimates contain frequency-dependent noise that arises from a variety of sources including local signals as well as global artifacts aliased into position estimates via satellite orbits, clock corrections, and others. One therefore must be careful in handling the underlying stochastic noise properties of the time series. Several works (Mao et al. 1999; Williams 2003) have shown that the noise in GPS daily position time series can be modeled as the sum of white and power-law noise. For this reason, HECTOR software (Bos et al. 2008) is used to perform stochastic analyses of the GPS time series, which includes both white and colored noise models. Generally, there is good agreement between the standard least squares and HECTOR, but the estimates using least squares result in much smaller uncertainties (Olivares and Teferle 2013; Montillet and Yu 2014).

\section{Observed Structural Deformation}

\section{Evergreen Floating Bridge}

Averaged over the 2012-2013 year, GPS measurements show positioning error scatter of $2.4 \mathrm{~cm}$. Outliers are controlled predominantly by pseudorange multipath, which is confirmed through
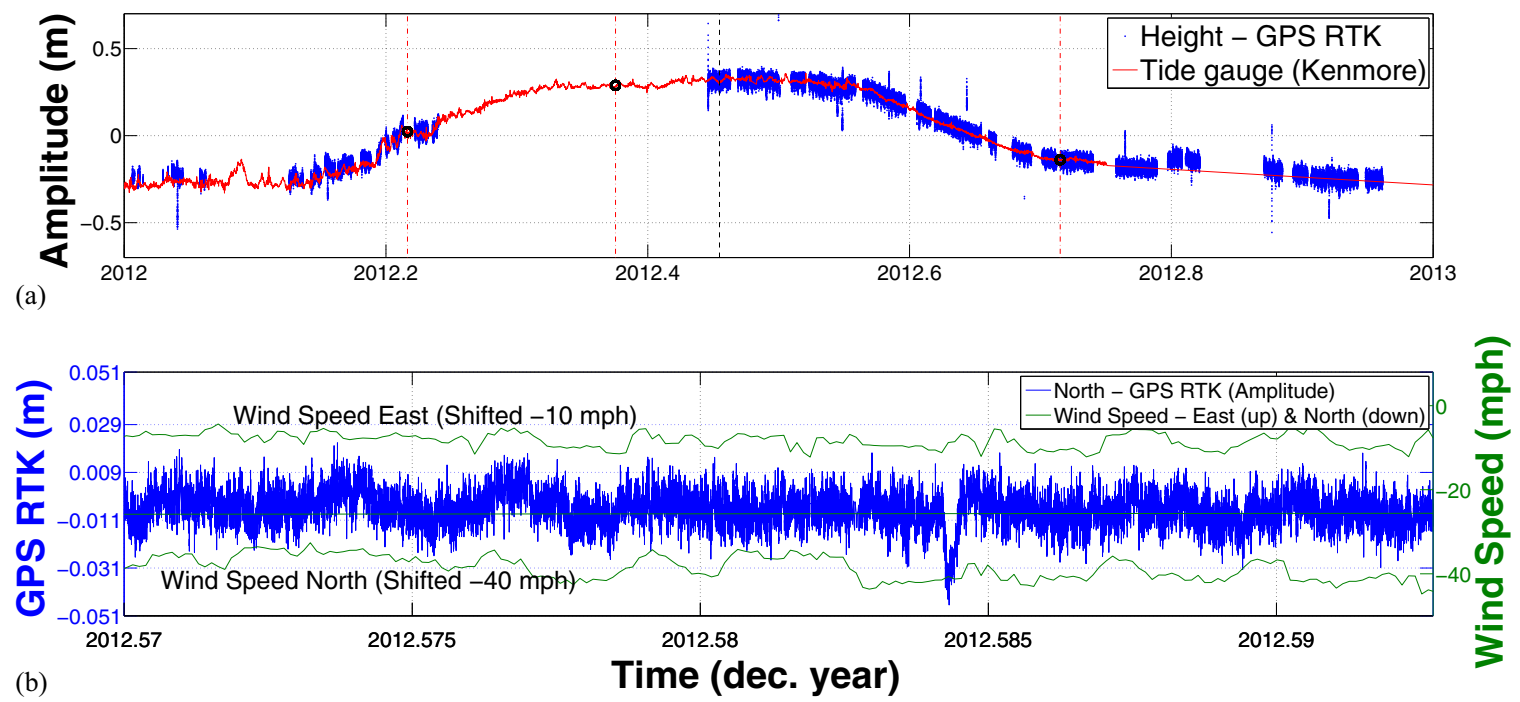

Fig. 5. (Color) (a) Downsampled real-time GPS height coordinate time series (blue) from station 520N (relative to station SEAT) and lake-level gauge measurements recorded at Kenmore tide gauge station on Lake Washington (red) and lake-level measured by the USACE during cable tightening of the bridge anchors (black dots); (b) east and north wind speed and north component (bridge perpendicular) 520N GPS station RTK data 
examination of the signal-to-noise stream output from the GPS receiver and by cycle slips in carrier-phase tracking. Fig. 5 shows the height coordinate of $520 \mathrm{~N}$ (blue) as they were available in real time, but with outliers from known cycle slips removed. The large amplitude and annual period sinusoidal signal $(\sim 60 \mathrm{~cm})$ dominating the vertical measurements stems from the bridge floating on the seasonally varying height level of the lake. Lake level is controlled by USACE via shipping locks that control flow to the Pacific Ocean in Puget Sound. Tide gauge data measured at Kenmore, Washington, to the north of $520 \mathrm{~N}$, are shown in red along with intermittent lake levels measured by USACE (black dots) made at the ocean locks. Data outages happen because access to service the $520 \mathrm{~N}$ receiver requires traffic disruption via infrequently granted governmentissued lane-closure permits.

At the bottom of Fig. 5(b), the north component of the GPS receiver position is shown together with the north and east components of the wind speed recorded at a weather station very close to the structure. Given both the predominant winds, which are oriented north/south along the glacially carved Lake Washington, and the east-west orientation of the bridge crossing it, one would expect some north-south displacements of the bridge during times of high winds and their attendant winddriven waves striking the bridge, rather than an east-west component. However, the floating bridge position does not show any perturbations by winds up to $74 \mathrm{~km} / \mathrm{h}$ (40 knots) or its waves, which can sometimes become large enough that their spray over the deck forces temporary closure of the bridge. Moreover, both the wind data and the tide gauge time series (that record winddriven lake-level variations) show that the high-wind period lasted from January to June and restarted in November of the same year (Fig. 5), but the variance of the $520 \mathrm{~N}$ position time series does not change throughout the year. From this it is concluded that the bridge is insensitive to wind and wave forces.

Another load on the bridge is traffic volume, which can vary between just a few cars present during early morning hours to over a thousand cars present on the bridge during peak usage. The floating bridge must respond to the weight of the automobiles, which might be expected to generate strains or show vertical subsidence of the bridge from its equilibrium flotation level (Inaudi et al. 2000), but none are apparent in the vertical, which is the least well-resolved component of position. However, we do observe a daily east-west position oscillation that is readily visible in raw time series (dE in Fig. 6). The signal shows a 24-h period, sinusoidal oscillation with a $1.3-\mathrm{cm}( \pm 0.4-\mathrm{cm})$ amplitude that is constant, along with it phase, throughout the year. This oscillation is not visible in the north-south (or vertical) components of motion. An $\sim 2$-cm offset to the north (black ellipse) simultaneous with adjustment of the anchor cables that attach the floating bridge to the lake bottom shows that the GPS unit is not insensitive to north-south position fluctuations, so clearly the observed oscillation is not multipath; rather it is real and confined to the east-west.

Fig. 6 shows the $520 \mathrm{~N}$ position time series plotted alongside the total traffic volume as measured in cars per hour (statistics provided

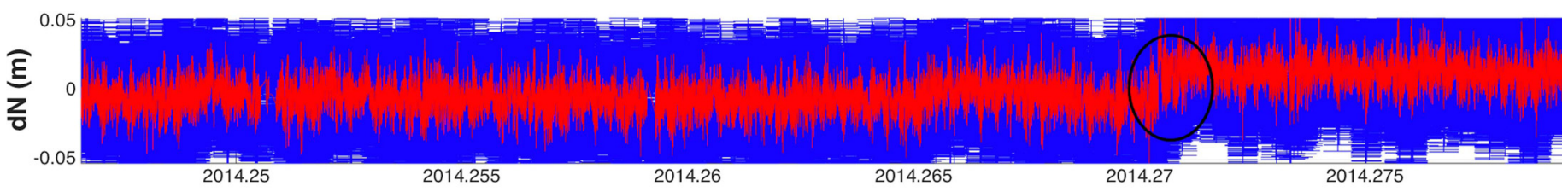

(a)

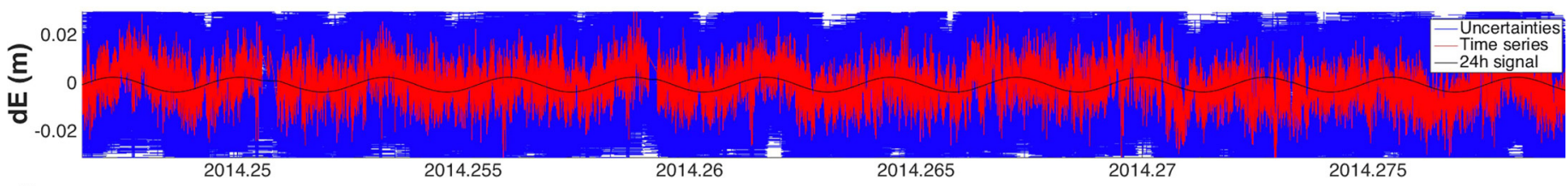

(b)

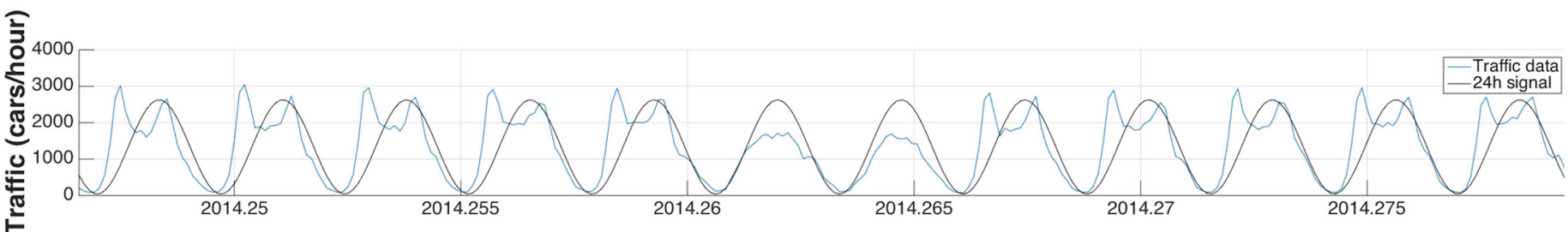

(c)

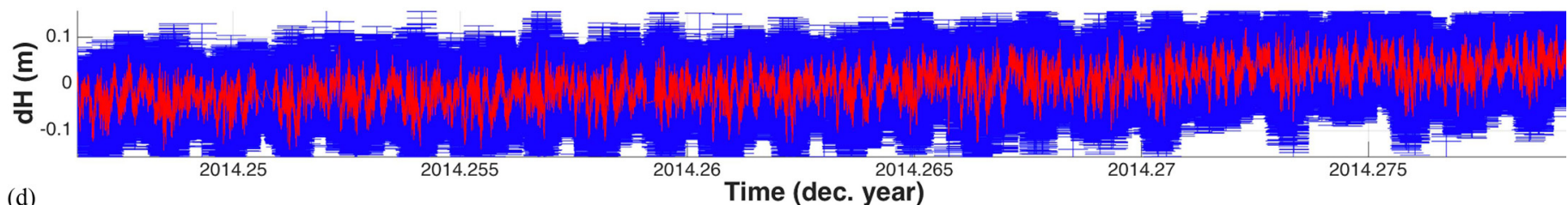

(d)

Time (dec. year)

Fig. 6. (Color) (a, b, d) Time series of GPS receiver coordinates at the station 520N, together with (c) the traffic load on the floating bridge (SR520) over Lake Washington; ellipse (a) shows the north-south GPS resolution of the bridge's response to the tightening of its anchor cables 
by WSDOT). Bridge vehicle density is characterized on weekdays as peaking during two "rush-hour" spikes when a high density of commuter vehicles moves in and out of Seattle. On weekends, the vehicle flows peak midday without the rush-hour spikes, but all days follow the 24-h phase. From an engineering standpoint, it is not understood why the periodic oscillations show up primarily on the east-west direction, given that the orientation of the bridge is situated only $15^{\circ}$ from due east-west, making north-south swaying of the bridge seem most likely. The source may be related to the traffic-induced load change on the bridge, or it may be related to some other process that also exhibits a 24-h periodicity, for example, daily temperature and attendant thermal expansion of the floating bridge. Because the signal is isolated to the east-west component, it is unlikely to be multipath, which nearly always shows up on all three components of motion. Either way, with just the single $520 \mathrm{~N}$ time series it is possible only to show that the bridge undergoes a 1.3 -cm daily east-west periodic oscillation at its center span, whereas an array of GNSS stations along the bridge would likely be able to distinguish between different causal forcing mechanisms.

\section{Alaskan Way Viaduct Elevated Freeway}

For the subsiding Alaskan Way Viaduct the focus here is on long-term deformation recorded with the daily postprocessed time series. For these data additional continuous GPS stations from the regional Pacific Northwest Geodetic Array (PANGA) are included to define a regional reference frame that averages out any motion at a single reference station that could otherwise be aliased into apparent deformation within the viaduct. For this purpose, a group of surrounding stations, ELSR, KTBW, LSIG, P426, PFLD, SEAT, and YELM, is used [Fig. 7(a)], all of which have at least 10 years of data and whose velocities and noise characteristics are well established (Riel et al. 2014). In the parameterization it is assumed that subsidence of the viaduct is steady state through time, so a linear rate is estimated simultaneously with known offsets caused by well-characterized slow earthquakes along the underlying Cascadia subduction zone fault that regionally deforms the GPS network but whose impact is well understood (Szeliga et al. 2008). The length of the intervals is chosen to have long GPS time series with which to estimate precisely the tectonic rate, because short time series (less than approximately 2 years) can yield biased rates with large uncertainties (Montillet et al. 2015). Data from V096 and V102 were therefore processed in two batches, from 2010 to 2013 and again from 2010 to mid-2014, because monitoring of the viaduct structure was stopped in early 2014. Fig. 7(a) shows the tectonic movement around Puget Sound estimated with all the available observations between 2010 and 2014, with linear rates of motion estimated with the least-squares method. The estimates assuming the colored-noise statistics in HECTOR are tabulated in Tables $1-3$ in the Appendix. The results generally agree between the two methods but with larger uncertainties associated with colored-noise estimates.

For stations V096 and V102 [displayed in Fig. 7(b)], V096 shows east-west motion nearly identical to the regional velocity field, as measured at the closest stations LSIG and PFLD, which indicates no anomalous motion of the northern part of the viaduct with respect to ongoing regional spatial pattern of deformation of the underlying earth. Vectors from station V102, however, do not agree with the regional velocity field in either the time interval 2010-2013 or 2010-2014, or with V096. Given that the baseline between V096 and V102 is less than $500 \mathrm{~m}$, their velocities should be nearly identical if the viaduct was not deforming internally. Therefore, it is clear that there is northeast-directed deformation within the southern half of the viaduct structure as measured at V102. Strain within the viaduct itself can be estimated by subtracting the estimated tectonic rate from V096 and V102, as shown in Tables 1 and 2 (Appendix) and the results are shown as red (2010-2014) and blue (20102013) arrows. The estimates change from a displacement of approximately $4.3 \mathrm{~mm} /$ year on the east and $2 \mathrm{~mm} /$ year on the north coordinates in the 2010-2013 time interval to 7.6 and 3.1 $\mathrm{mm} /$ year (respectively) in the 2010-2014 time period.

The uncertainties associated with the displacement are relatively small $(<0.14 \mathrm{~mm} /$ year). When using HECTOR, the displacements for either the 2010-2013 or 2010-2014 data intervals are similar, but the uncertainties associated with the estimates are larger and more realistic as a result of using a full stochastic model with colored noise. For the vertical motion, the measurements show subsidence of approximately 3 to $4 \mathrm{~mm} /$ year between the two stations (V102 and V096), with V102 subsiding (see Table 3) relative to V096.

\section{Howard A. Hanson Dam}

The position scatter of all daily position data from 14 stations mounted on Howard A. Hanson Dam average 2, 4, and $7 \mathrm{~mm}$ in the north, east, and vertical components of motion over the 2.5 years of occupation during 2010-2012. Generally, the dam network was stable and showed no evidence of internal deformation within the earth-fill dam itself or its surrounding areas as measured on 12 of the 14 GPS stations deployed throughout the dam.

The one notable exception occurred in 2010.8, when two adjacent stations (TWR1 and BRDG), located on a tower and its access bridge at the southernmost end of the dam, simultaneously displaced southward over a 1-month period starting in 2010.8 and ending in 2019.9. Fig. 8 shows 1 year of data between 2010.4 and 2011.4. During this time none of the remaining 12 GPS stations located away from the south end of the dam showed resolvable motion, confirming that this signal is localized to the south end of the dam and is neither a reference frame nor data processing artifact. The timing of the onset of the southerly deformation of BRDG and TWR1 coincides with the start of water filling an excavated pit (30 m deep, $40 \times 30 \mathrm{~m}$ wide) located directly adjacent to the dam. The separation between the edge of the pit nearest the dam and the closest GPS station on the dam, TWR1, is 11 $\mathrm{m}$, and the next closest, BRDG, is $18 \mathrm{~m}$. The transient motion at TWR1 and BRDG begins at the start of filling the pit with water, prior to which it was left empty. It is inferred that the onset of filling it induced a local hydrological response that perturbed the local substrate of the dam's bridge and tower. The square in Fig. 8 emphasizes the 1-month duration of anomalous deformation, which reaches a total southerly offset $4.9 \pm 0.5$ and $3.0 \pm 0.7$ $\mathrm{mm}$ at TWR1 and BRDG, respectively. TWR1 also shows $2.3 \pm 0.4 \mathrm{~mm}$ of easterly offset, but delayed by roughly 20 days. No corresponding up-down deformation can be identified on the time series at these two stations, or on any of the other 12 stations, suggesting that the observed deformation is a primarily south-directed transient motion directed toward the excavated pit. Although a variety of mechanisms might be invoked to explain the anomalous southerly motion, it is consistent with a simple diffusion response of the substrate beneath BRDG and TWR1. This is supported by the linear trend of the observed anomalous deformation, as well as the lack of observable rebound after the pit was filled. It is also possible that the observed deformation may be explained by an inelastic, viscous response of soil, which is reasonably fit by an exponential fit to 


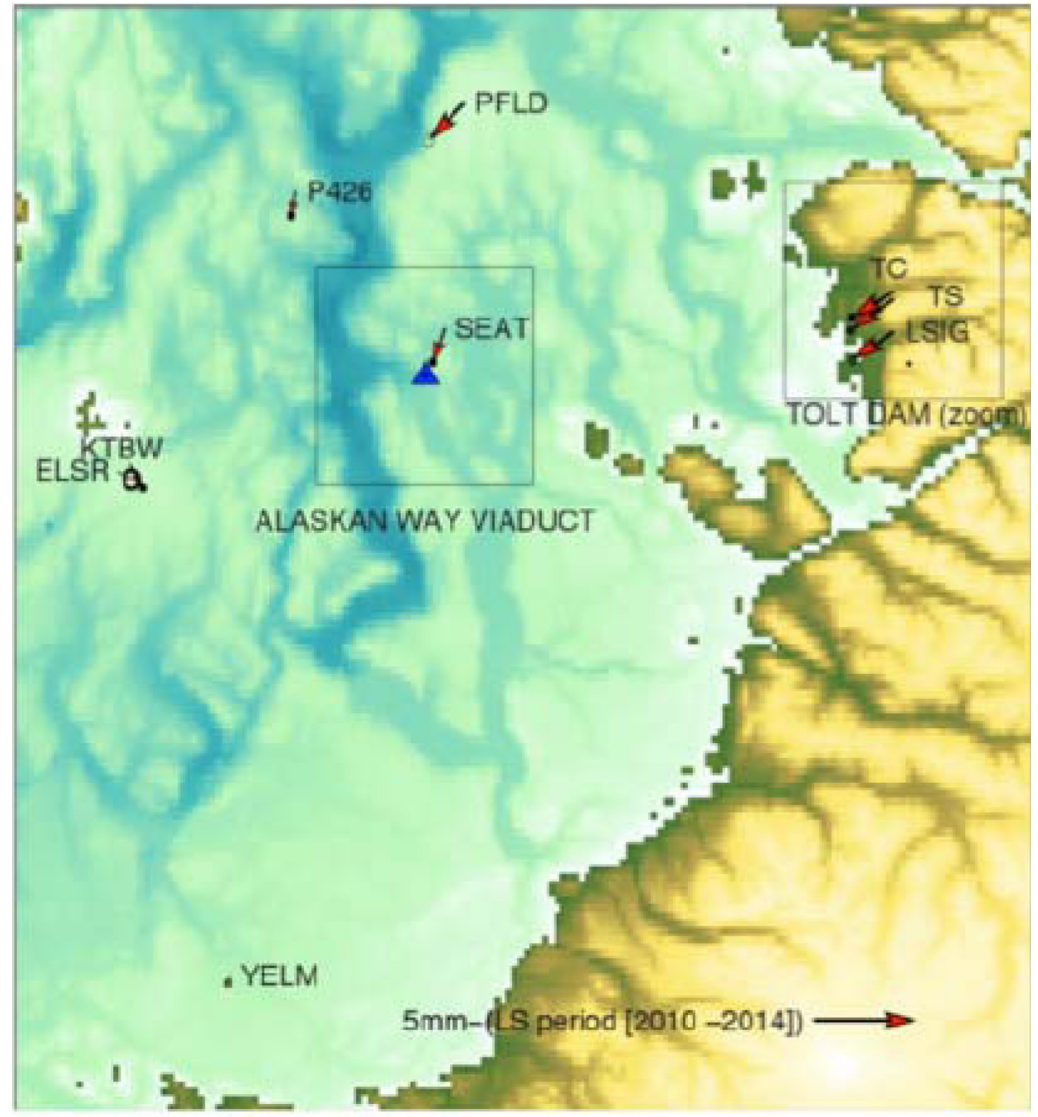

(a)

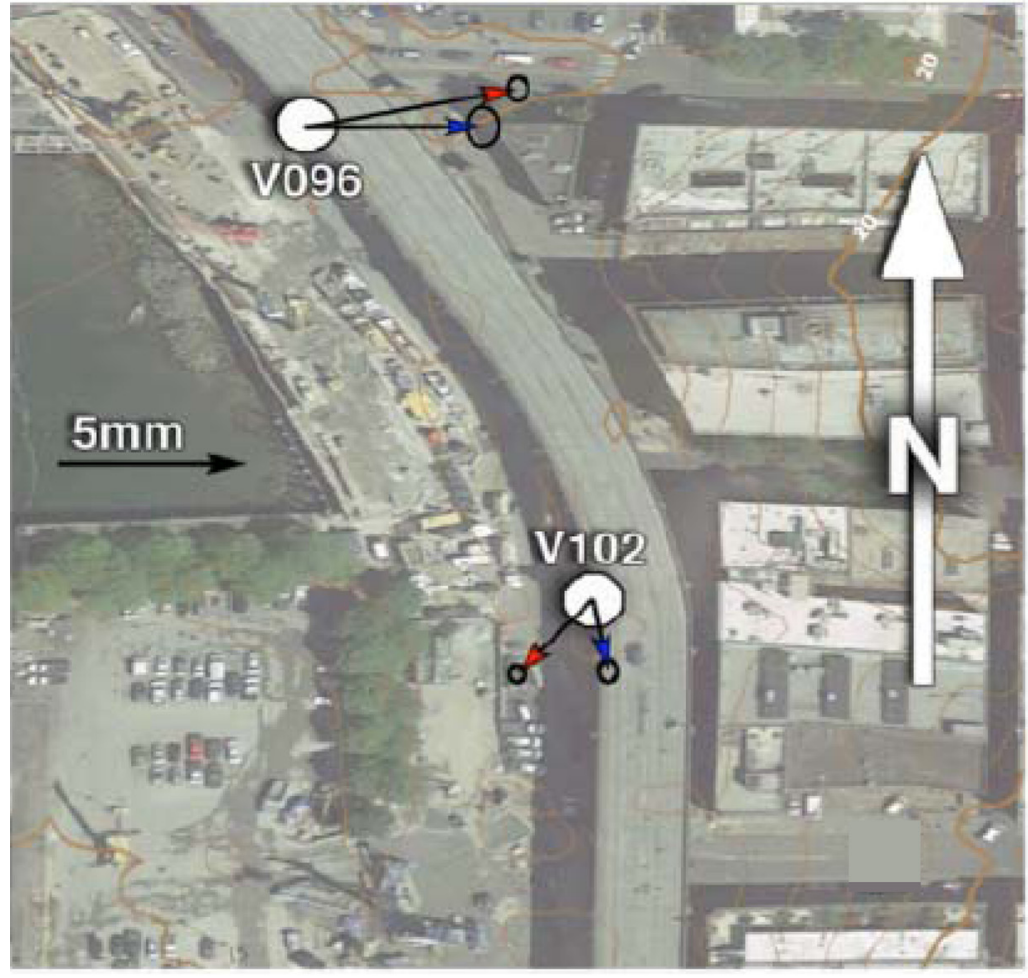

(b)

Fig. 7. (Color) (a) Estimated east and north residual motions from both the viaduct and surrounding regional network together with uncertainties (ellipses) based on least squares; (b) stations located on top of the viaduct together with the displacement east and north directions; the estimates computed using the period from 2010 to 2013 are displayed with blue arrows, and the red arrows are the results using the period from 2010 to 2014 (Imagery @ 2015 Google, Landsat, USDA Farm Service Agency, Map data) 


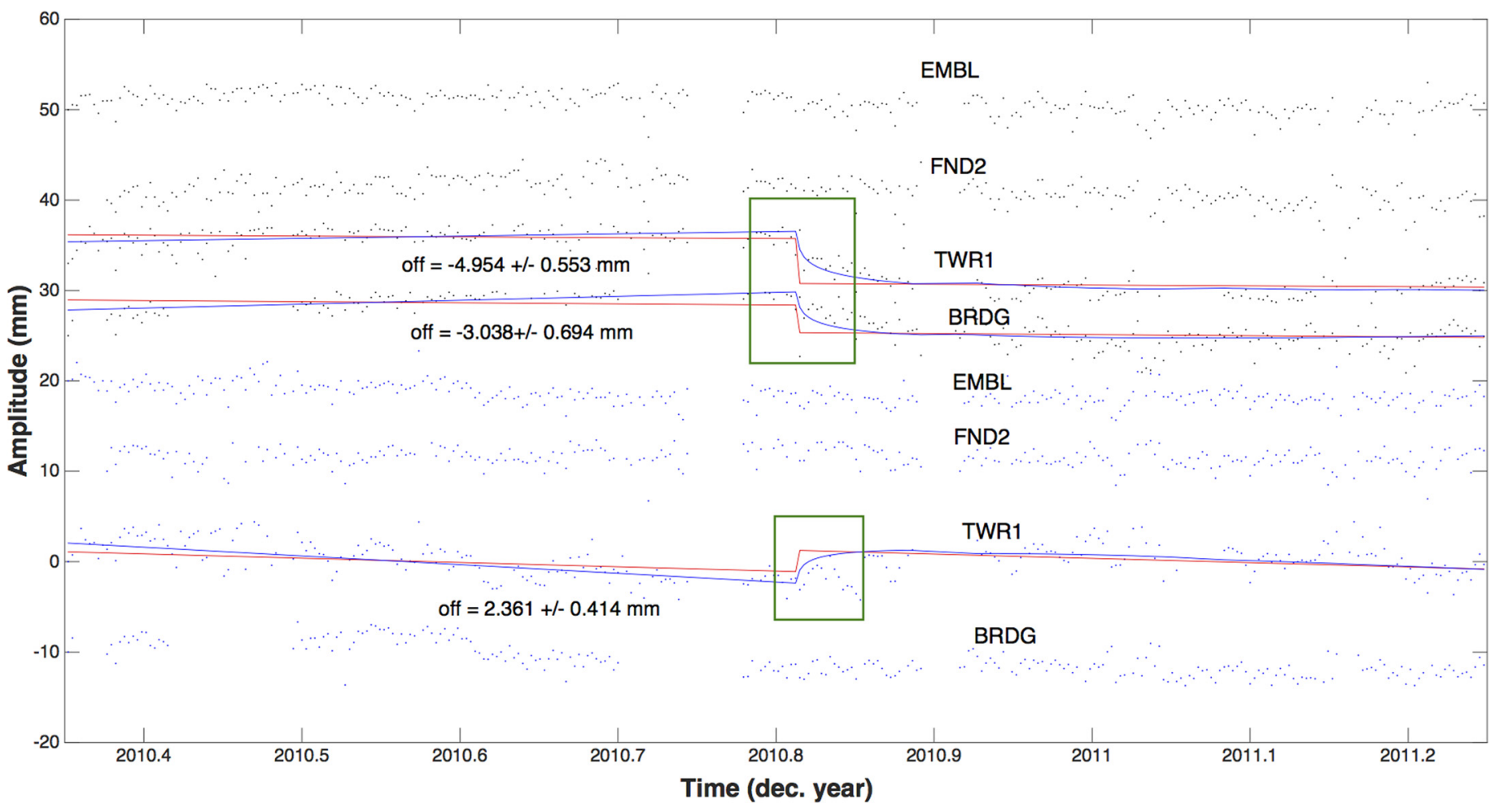

Fig. 8. (Color) North and east coordinates of four GPS stations located on Howard A. Hanson Dam: the two nearest the southern end of the dam closest to the excavated pit show transient deformation simultaneous with pit refilling (TWR1 and BRDG), whereas the remainder ( 2 of 12 shown) that are further away from excavation show no anomalous positions; the square highlights the displacement at the time 2010.82 with the estimated offset using either a step function or a logarithmic function with a 66-day relaxation time

the data (as shown in Fig. 8), but discriminating between the two mechanisms is not possible with the available data.

\section{Tolt Dam}

Unlike the three previous structures described previously, GPS stations on Tolt Dam were installed as one component of a dam safety monitoring system by its operator, and the resultant real-time position time series were monitored for anomalous motion and tied to an alarm system. Fig. 9 shows the daily positions of three Tolt Dam stations, LSIG, TS, and TC. Superimposed on the time series are least-squares fits of a model (Model A in Fig. 9) including tectonic motion, annual and semiannual signals of constant amplitude and phase, and offsets caused by known geophysical events (primarily Cascadia subduction zone slow earthquakes) and hardware changes (Montillet et al. 2015). For the vertical position time series, the tectonic rate is omitted (Model B) because no long-term uplift is expected (observed). Fig. 9 also shows the pool level of Tolt Reservoir, which is lowered in early spring in anticipation of the melting snowpack and refilled throughout the remainder of the year.

Because both the annual regional signal and the annual snowmelt-driven lake-level rise are both seasonally driven (stationary phase), it is difficult to discriminate between the well-established regional pattern of annual deformation versus any additional deformation of the dam-mounted stations TC and TS in response to the variable reservoir level behind the dam. One can show that for the two Tolt stations, TC and TS, the annual signal shows a smaller amplitude than that at the bedrock reference station LSIG $\sim 100 \mathrm{~m}$ away, which is consistent with the regional signal. This suggests that the dam may isolate the overlying GPS receivers from the regional seasonal oscillation. The GPS measurements also show that Tolt Dam is not significantly impacted by varying the reservoir level, which contrasts, as expected, with concretearch dams in which some flexure is expected with varying reservoir levels. For instance, Hudnut and Behr (1998) and Barzaghi et al. (2012) showed that GPS receivers on the Pacoima, CA, concrete-arch dam responded to annual variations in temperature and hydrological load.

In real time, the data from the Tolt Dam are considerably more scattered than the other deployments previously described, because the structure lies in a deep valley with narrow sky view that both limits the number of satellites and amplifies pseudorange multipath by the surrounding topography. Multipath in particular has been shown to be the limiting factor in high-rate positioning accuracy (Bond et al. 2011). It was found that measurement accuracy is degraded to 2 - to 3 -cm accuracy even over the relatively short baselines used at Tolt Dam. Fig. 10 shows 1.5 months of real-time, highrate data from station TS. The obvious 24-h oscillation of the position, which varies between $\sim 1 \mathrm{~cm}$ on the north and east component to $2-3 \mathrm{~cm}$ on the vertical, is nearly entirely caused by pseudorange multipath, which repeats every sidereal day. Although a variety of techniques can reduce multipath (i.e., sidereal and spatial filters), multipath will likely remain the largest source of positioning error and limit the extent real-time GPS or even GNSS can be used for monitoring structures located in deep valleys.

\section{Conclusions}

The four GPS deployments discussed here were designed specifically to measure and quantify suspected deformation within 


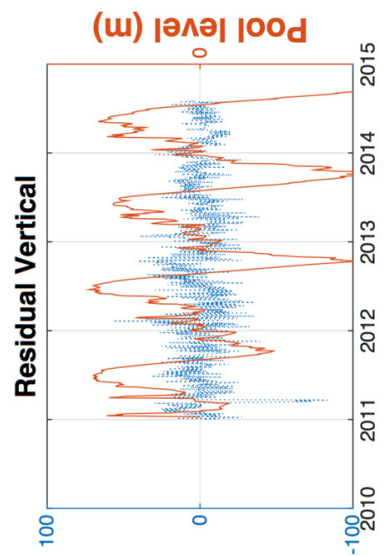

(u) |ә^ә| |00d
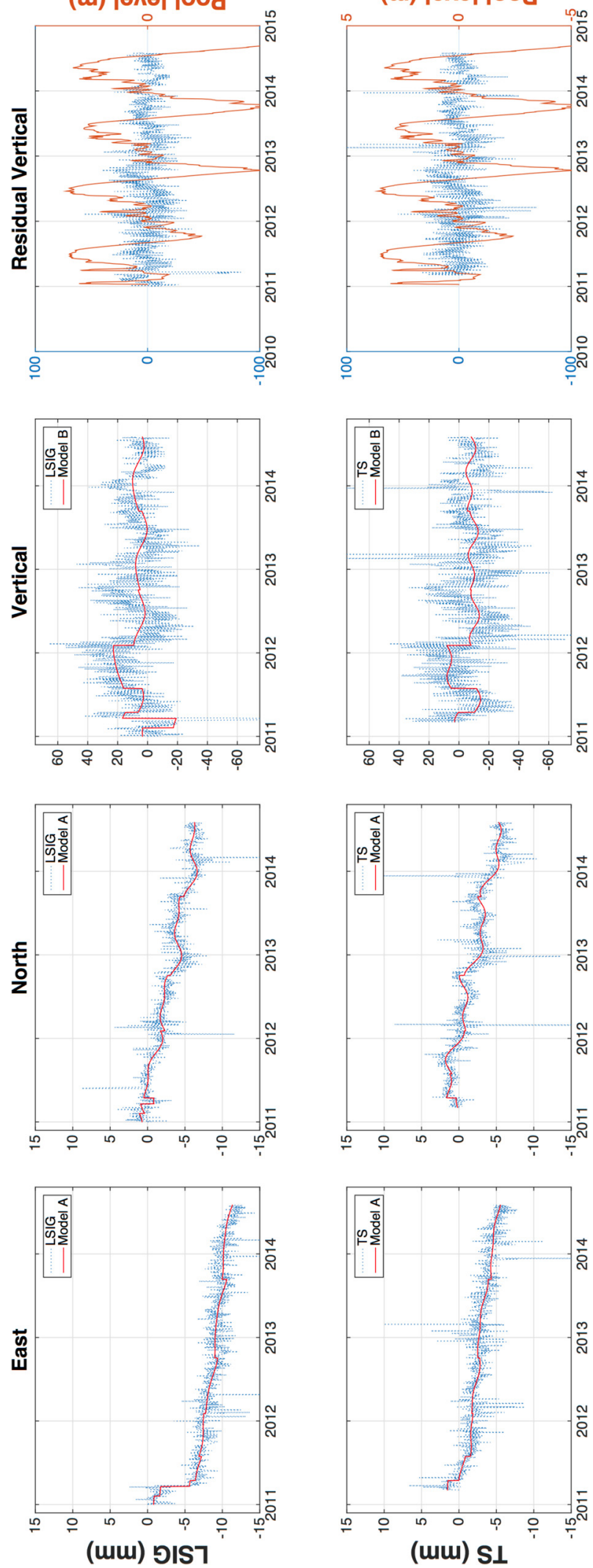

(w) |ә^ә| |00d
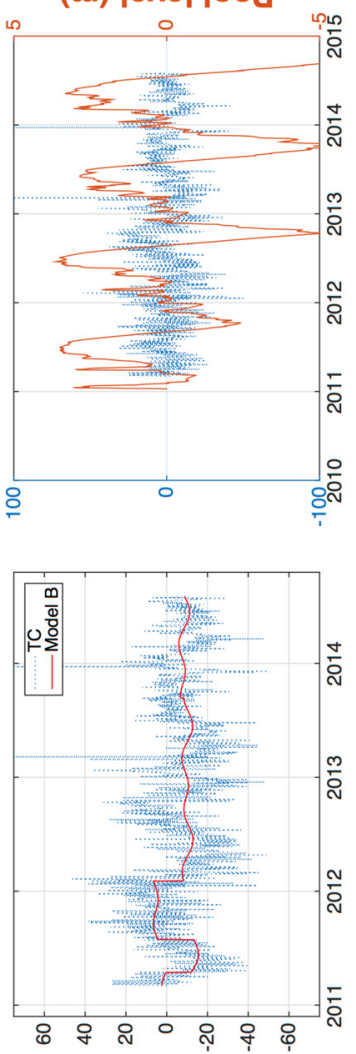

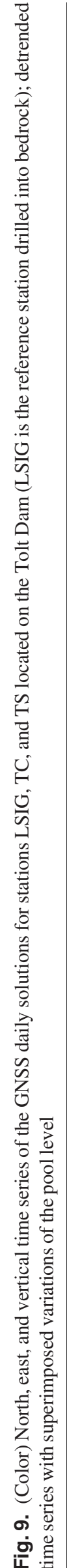
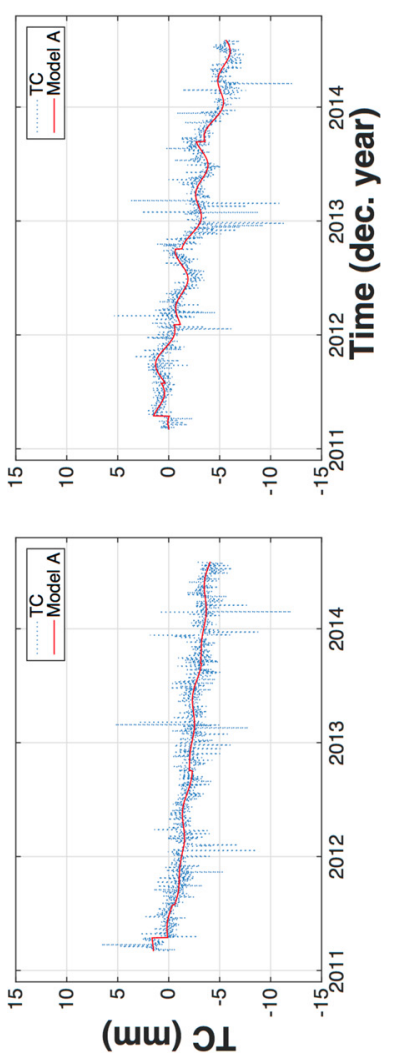

J. Surv. Eng. 


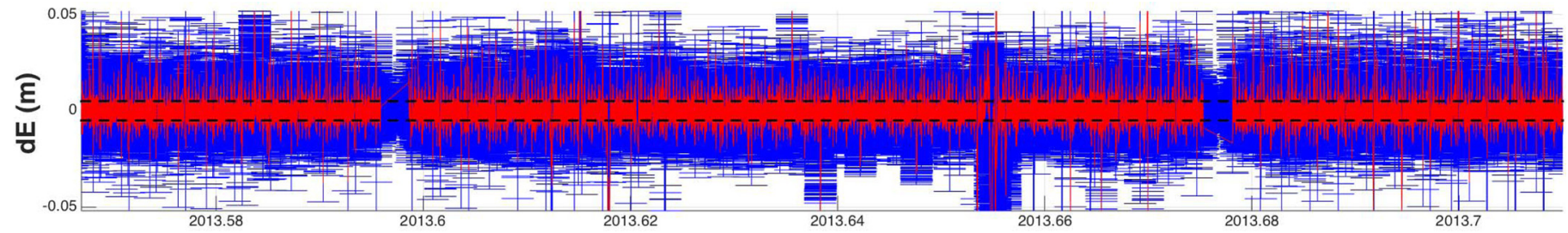

(a)

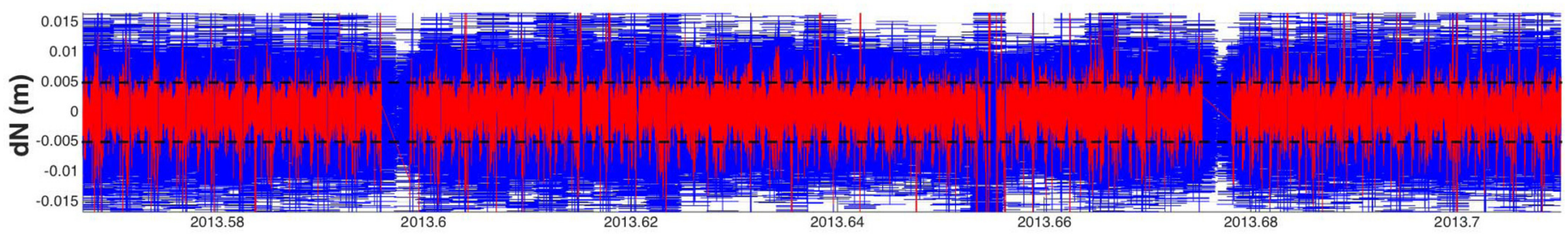

(b)

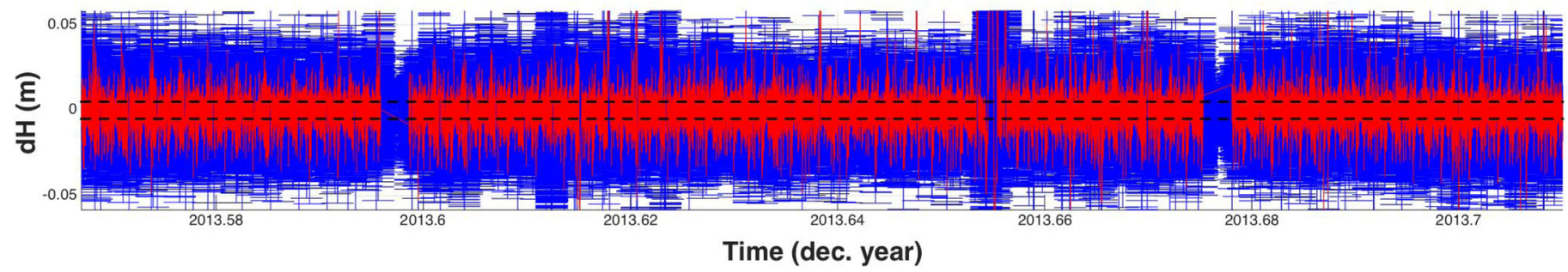

(c)

Fig. 10. (Color) Time series of GPS receiver coordinates for the station TS estimated in real time with LSIG as a fixed reference station $200 \mathrm{~m}$ from TS and TC, uncertainties for the (a) east, (b) north, and (c) height with dashed lines ( $\pm 5 \mathrm{~mm}$ )

critical civil-engineered structures, both in real time for safety monitoring purposes and retrospectively with precise daily positions suitable for identifying longer term and subtler transients. Three of the four structures show resolvable deformation signals, which shows the usefulness of relatively low-cost GPS monitoring. The processing time for the real-time analysis is negligible using predicted satellite ephemerides, which provide sufficient accuracy over short baselines (less than approximately $1 \mathrm{~km}$ ). Daily position, in contrast, optimized for positioning accuracy, requires final orbits, which mandates a delay of typically 7 days.

Although the variable level of the floating bridge was known from lake-level measurements, the $1.3-\mathrm{cm}$ east-west signal generated by variable traffic loads was not. For the elevated freeway, ongoing subsidence of $4 \mathrm{~mm} /$ year previously noted by semiannual optical surveys was confirmed, but the GPS measurements show the approximately 6-mm lateral snaking pattern of strain along the structure. At the Howard A. Hanson Dam, the GPS measurements detected the response of the southernmost portion of the dam to filling a 30-m-deep excavated pit with water, which was not noticed previously. At Tolt Dam, the GPS observations show that the dam does not respond appreciably to water-level variations in the reservoir, unlike concrete-arch dams. It also suggests that the earth-filled dam to some degree isolates its two GPS stations from the regional annual deformation pattern (hydrological signal) seen on over 300 other stations located throughout the Pacific Northwest.

In the seismically active Western United States and other areas, real-time, GPS critical infrastructure monitoring offers the potential to significantly improve response times for monitoring or identifying anomalous deformation, for instance, following earthquakes, for the betterment of public safety. Structural engineers stand to benefit as well, particularly in determining when to close structures, or conversely, when they may be kept open, for example, through rapid assessment following earthquakes. Similarly, this study shows that the postprocessed daily positions can accurately quantify millimeterlevel deformations within heavy civil-engineered structures, which is also of use in long-term structural preservation.

As GPS proliferates and available processing systems increasingly take advantage of new constellations, noise sources will continue to be actively reduced and the positioning precision will increase. Current surveying accuracy requirements are subcentimeter, which still presents a challenge for epoch-by-epoch GPS measurements, particularly if limited sky view is a site constraint. Pseudorange multipath is the biggest error source, and one way to reduce multipath is to install an array of antennas at each station (spatial filtering) together with regular carrier-phase techniques (Kyuhong et al. 2004). However, as deployment costs continue to drop, GPS may increasingly be deployed as both a real-time monitoring and long-deformation measurement. It may eventually supplant existing optical systems that have been routinely used for over a century but are prohibitively expensive for continuous and real-time applications.

\section{Appendix. Additional Results in the Analysis of the Alaskan Way Viaduct Deformations}

The estimates assuming the colored-noise statistics in HECTOR are tabulated in Tables 1-3. These results can be compared with the estimates shown in Fig. 7. 
Table 1. Estimated Velocity $(\mu)$ and Associated Uncertainties $(\sigma)$ for Some Stations around the Alaskan Way Viaduct Using the Least Squares with Data Intervals 2010-2012 and 2010-2014

\begin{tabular}{|c|c|c|c|c|c|c|c|c|}
\hline \multirow{3}{*}{$\begin{array}{l}\text { Least } \\
\text { squares }\end{array}$} & \multicolumn{4}{|c|}{ 2010-2013 } & \multicolumn{4}{|c|}{ 2010-2014 } \\
\hline & \multicolumn{2}{|c|}{$\begin{array}{c}\text { East } \\
\text { (mm/year) }\end{array}$} & \multicolumn{2}{|c|}{$\begin{array}{c}\text { North } \\
\text { (mm/year) }\end{array}$} & \multicolumn{2}{|c|}{$\begin{array}{c}\text { East } \\
\text { (mm/year) }\end{array}$} & \multicolumn{2}{|c|}{$\begin{array}{c}\text { North } \\
\text { (mm/year) }\end{array}$} \\
\hline & $\mu$ & $\sigma$ & $\mu$ & $\sigma$ & $\mu$ & $\sigma$ & $\mu$ & $\sigma$ \\
\hline ELSR & 1.34 & 0.19 & -0.58 & 0.24 & 0.68 & 0.15 & -0.38 & 0.19 \\
\hline KTBW & 0.71 & 0.06 & -1.70 & 0.07 & 0.60 & 0.03 & -1.19 & 0.04 \\
\hline LSIG & -2.54 & 0.14 & -1.86 & 0.18 & -2.07 & 0.05 & -1.40 & 0.07 \\
\hline P426 & -0.15 & 0.06 & -1.12 & 0.07 & -0.22 & 0.04 & -1.24 & 0.05 \\
\hline PFLD & -1.88 & 0.11 & -1.81 & 0.14 & -1.72 & 0.10 & -1.84 & 0.12 \\
\hline SEAT & -0.37 & 0.06 & -2.10 & 0.08 & -0.55 & 0.03 & -1.67 & 0.04 \\
\hline V096 & 4.71 & 0.17 & 0.02 & 0.21 & 5.64 & 0.10 & 1.05 & 0.13 \\
\hline V102 & 0.39 & 0.10 & -2.00 & 0.13 & -2.02 & 0.08 & -2.08 & 0.10 \\
\hline YELM & -0.08 & 0.10 & -0.90 & 0.12 & -0.12 & 0.05 & -0.38 & 0.06 \\
\hline$\Delta \mathrm{V} 102-\mathrm{V} 096$ & -4.32 & 0.13 & -2.02 & 0.17 & -7.67 & 0.09 & -3.14 & 0.11 \\
\hline
\end{tabular}

Note: The last row shows the difference between station V102 and V096 on the estimated east and north tectonic rate. Bold $=$ the average of the uncertainties.

Table 2. Estimated Velocity $(\mu)$ and Associated Uncertainties $(\sigma)$ for Some Stations around the Alaskan Way Viaduct Using the HECTOR with the Data Intervals 2010-2012 and 2010-2014

\begin{tabular}{|c|c|c|c|c|c|c|c|c|}
\hline \multirow[b]{3}{*}{ HECTOR } & \multicolumn{4}{|c|}{ 2010-2013 } & \multicolumn{4}{|c|}{ 2010-2014 } \\
\hline & \multicolumn{2}{|c|}{$\begin{array}{c}\text { East } \\
\text { (mm/year) }\end{array}$} & \multicolumn{2}{|c|}{$\begin{array}{c}\text { North } \\
\text { (mm/year) }\end{array}$} & \multicolumn{2}{|c|}{$\begin{array}{c}\text { East } \\
\text { (mm/year) }\end{array}$} & \multicolumn{2}{|c|}{$\begin{array}{c}\text { North } \\
\text { (mm/year) }\end{array}$} \\
\hline & $\mu$ & $\sigma$ & $\mu$ & $\sigma$ & $\mu$ & $\sigma$ & $\mu$ & $\sigma$ \\
\hline ELSR & 0.78 & 0.59 & -0.66 & 0.60 & 0.68 & 0.23 & -0.24 & 0.24 \\
\hline KTBW & 0.44 & 0.65 & -0.98 & 0.55 & 0.48 & 0.13 & -1.24 & 0.14 \\
\hline LSIG & -2.52 & 0.40 & -1.81 & 0.23 & -2.04 & 0.13 & -1.42 & 0.10 \\
\hline P426 & -0.75 & 0.51 & -1.50 & 0.23 & -0.34 & 0.41 & -1.19 & 0.10 \\
\hline PFLD & -1.55 & 0.26 & -1.75 & 0.18 & -1.38 & 0.22 & -1.63 & 0.15 \\
\hline SEAT & -1.04 & 0.61 & -1.89 & 0.25 & -0.91 & 0.37 & -1.58 & 0.17 \\
\hline V096 & 3.71 & 2.10 & 1.74 & 1.19 & 5.26 & 1.32 & 1.07 & 0.48 \\
\hline V102 & -0.93 & 0.99 & -1.82 & 0.83 & -2.92 & 1.03 & -2.21 & 0.40 \\
\hline YELM & 0.05 & 0.83 & -0.52 & 0.54 & -0.30 & 0.43 & -0.76 & 0.29 \\
\hline$\Delta V 102-V 096$ & -4.65 & 1.55 & -3.56 & 1.01 & -8.18 & 1.17 & -3.29 & 0.44 \\
\hline
\end{tabular}

Note: The last row shows the difference between station V102 and V096 on the estimated east and north tectonic rate.

\section{Acknowledgments}

The deployment of continuous GPS monitoring was enabled by Cooperative Agreement Grant G15AC00062 to the Pacific Northwest Geodetic Array at Central Washington University by the U.S. Geological Survey National Earthquake Hazards Pro-gram. Additional real-time analysis techniques were developed under National Aeronautics and Space Administration Research Opportunities in Solid Earth Sciences Grant NNX1OAD15G. Additional construction, operations, and maintenance support were provided by the City of Seattle. The authors thank the Seattle District of the USACE, WSDOT, and the City of Seattle for permission and assistance in GPS receiver installation and maintenance. Raw satellite observations from all GPS stations described in this paper are archived and may be downloaded from the data portal of the Pacific Northwest Geodetic Array at Central Washington University together with corresponding metadata. Hydrological data are available from the USGS. Road traffic data were provided by WSDOT.

\section{References}

Altamimi, Z., Collilieux, X., and Métivier, L. (2011). "ITRF2008: an Improved solution of the international terrestrial reference frame." $J$ Geod., 85(8), 457-473.

Barzaghi, R., Pinto, L., and Monaci, R. (2012). "The monitoring of gravity dams: Two test in Sardinia, Italy." Proc., FIG Working Week 2012, Rome.

Blewitt, G. (1993). "Advances in global positioning system technology for geodynamics investigations: 1978-1992." Contributions of space geodesy to geodynamics: Technology, D. E. Smith and D. L. Turcotte, eds., American Geophysical Union, Washington, DC.

Boehm, J., Werl, B., and Schuh, H. (2006). "Troposphere mapping functions for GPS and very long baseline interferometry from European Centre for Medium-Range Weather Forecasts operational analysis data." J. Geophys. Res., 111(B2), B02406.

Bond, J., Kim, D., and Fletcher, J. (2011). "A study of the use of GPS sensors for structural monitoring of the Mactaquac Dam." 〈http://www.gemeni -navsoft.com/GPS_Structural_monitoring.pdf-2011>

Bos, M., Fernandes, R., Williams, S., and Bastos, L. (2008). "Fast error analysis of continuous GPS observations." J Geod., 82(3), 157-166.

Çelebi, M., Prescott, W., Stein, R., Hudnut, K., Behr, J., and Wilson, S. (1999). "GPS monitoring of dynamic behavior of long-period structures." Earth. Spectra, 15(1), 55-66.

Erdoğan, H., and Gülal, E. (2009). "The application of time series analysis to describe the dynamic movements of suspension bridges." Nonlinear Anal, 12(2), 1183-1196.

Table 3. Estimates $(\mu)$ of the Up Coordinates When Fitting a Linear Rate into the Time Series and Associated Uncertainties $(\sigma)$

\begin{tabular}{|c|c|c|c|c|c|c|c|c|}
\hline \multirow[b]{3}{*}{ Up (mm/year) } & \multicolumn{4}{|c|}{ Least squares } & \multicolumn{4}{|c|}{ HECTOR } \\
\hline & \multicolumn{2}{|c|}{ 2010-2013 } & \multicolumn{2}{|c|}{ 2010-2014 } & \multicolumn{2}{|c|}{ 2010-2013 } & \multicolumn{2}{|c|}{ 2010-2014 } \\
\hline & $\mu$ & $\sigma$ & $\mu$ & $\sigma$ & $\mu$ & $\sigma$ & $\mu$ & $\sigma$ \\
\hline ELSR & -12.54 & 1.65 & -0.03 & 1.10 & -13.47 & 8.51 & -2.31 & 3.96 \\
\hline KTBW & -6.76 & 0.51 & -3.37 & 0.27 & -11.52 & 7.32 & -3.44 & 1.57 \\
\hline LSIG & -3.14 & 0.97 & -2.65 & 0.35 & -22.33 & 11.85 & -7.13 & 3.34 \\
\hline P426 & -7.41 & 0.54 & -5.36 & 0.35 & -8.10 & 1.76 & -4.84 & 1.73 \\
\hline PFLD & -9.10 & 0.92 & -7.06 & 0.77 & -5.05 & 2.91 & -5.78 & 2.71 \\
\hline SEAT & -7.120 & 0.650 & -2.84 & 0.32 & -8.55 & 2.40 & -3.41 & 1.74 \\
\hline V096 & -11.49 & 1.11 & -5.22 & 0.62 & -11.92 & 5.13 & -5.66 & 3.006 \\
\hline V102 & -8.04 & 0.73 & -6.26 & 0.48 & -11.33 & 4.52 & -7.32 & 3.360 \\
\hline YELM & -7.29 & 0.78 & -3.15 & 0.35 & -8.76 & 6.79 & -2.55 & 2.031 \\
\hline$\Delta \mathrm{V} 102-\mathrm{V} 096$ & 3.44 & 0.92 & -1.04 & 0.55 & 0.59 & 4.83 & -1.66 & 3.18 \\
\hline
\end{tabular}

Note: The last row contains the values when differencing the estimated for the station V102 and V096. Bold = the average of the uncertainties over V102 and V096 stations. 
Guo, J., and Ge, S. (1997). "Research on displacement and frequency of tall buildings under wind loading using GPS." Proc., ION Conf., Kansas City, MO

Herring, T. A., King, R. W., and McClusky, S. C. (2010a). "GAMIT reference manual, release 10.4." 〈http://www-GPSg.mit.edu/ simon/gtgk /GAMIT_Ref.pdf $\rangle$

Herring, T. A., King, R. W., and McClusky S. C. (2010b). "GLOBK: Global Kalman filter VLBI and GPS analysis program (release 10.4)." Dept. of Earth Atmospheric, and Planetary Sciences, Massachusetts Institute of Technology, Cambridge, MA.

Hudnut K. W., and Behr, J. (1998). “A continuous GPS monitoring of structural deformation at Pacoima Dam, California." Seismol. Res. Lett., 69(4), 299-308.

Hyzak, M., Leach, M., and Duff, K. (1997). "Practical application of GPS to bridge deformation monitoring." Proc., Permanent Committee Meeting and Symp., FIG, Copenhagen, Denmark.

Inaudi, D., Casanova, N., Vurpillot, S., Glisic, B., Kronenberg, P., and Lloret, S. (2000). "Deformation monitoring during bridge refurbishment under traffic." Proc., 16th Congress of IABSE, Luzern, Switzerland.

Kouba, J., and Héroux, P. (2001). "Precise point positioning using IGS orbit and clock products." GPS Solutions, 5(2), 12-28.

Kyuhong, C., Bilich. A., Larson, K. M., and Axelrad, P. (2004). "Modified sidereal filtering: implications for high-rate GPS positioning." Geophys. Res. Lett., 31(22), L22608.

Mao, A., Harrison, C. G. A., and Dixon, T. H. (1999). "Noise in GPS coordinate time series." J. Geophys. Res., 104(2), 2797-2816.

Meng, X., Roberts, G. W., Dodson, A. H., Cosser, E., Barnes, J., and Rizos, C. (2004). "Impact of GPS satellite and pseudolite geometry on structural deformation monitoring: analytical and empirical studies." J. Geod., 77(12), 809-822.

Montillet, J.-P., Williams, S. D. P., Koulali, A., and McClusky, S. C. (2015). "Estimation of offsets in GPS time-series and application to the detection of earthquake deformation in the far-field." Geophys. J. Int., 200(2), 1205-1219.

Montillet, J-P., and Yu, K. (2014). "Modeling geodetic processes with Levy Alpha-Stable distribution and FARIMA." Math. Geosci., 47(6), 627-646.

Ogundipe, O., Roberts, G. W., and Brown, C. J. (2014). "GPS monitoring of a steel box girder viaduct. structure and infrastructure engineering." Struct. Infrastruct. Eng., 10(1), 25-40.
Olivares, G., and Teferle, F. N. (2013). "A Bayesian Monte Carlo Markov chain method for parameter estimation of fractional differenced Gaussian processes." IEEE Trans. Signal Process., 61(9), 2405-2412.

Psimoulis, P., and Stiros, S. (2012). "A supervised learning computer-based algorithm to derive the amplitude of oscillations of structures using noisy GPS and Robotic Theodolites (RTS) records." Comput. Struct., 92-93, 337-348.

Riel, B., Simons, M., Agram, P., and Zhan, Z. (2014). "Detecting transient signals in geodetic time series using sparse estimation techniques." J. Geophys. Res., 119(6), 5140-5160.

Roberts, G., Meng, X., and Dodson, A. (2004). "Integrating a Global Positioning System and accelerometers to monitor the deflection of bridges." J. Surv. Eng., 10.1061/(ASCE)0733-9453(2004)130: 2(65), 65-72.

Roberts, G. W., Meng, X., Dodson, A. H., and Cosser, E. (2002). "Multipath mitigation for bridge deformation monitoring." J. Global Positioning Syst., 1(1), 25-33.

Rutledge, D. R., Meyerholtz, S. Z., Brown, N., and Baldwin, C. (2006). "Dam stability: Assessing the performance of a GPS monitoring system." GPS World, 17(10), 26-33.

Seeber, G. (2003). Satellite geodesy, 2nd Ed., Walter de Gruyter, Berlin.

SPU (Seattle Public Utilities). (2005). "South Fork Tolt River Reservoir and Dam.”〈http://www.seattle.gov/util/cs/groups/public/@spu/@water /documents/webcontent/spu01_005926.pdf $\rangle$

Stewart, M., and Tsakiri, M. (2001). "Long-term dam surface monitoring using global positioning system." Electron. J. Geotech. Eng. 〈http: //www.ejge.com/2001/Ppr0118/Abs0118.htm>

Szeliga, W., Melbourne, T., Santillan, M., and Miller, M. (2008). "GPS constraints on 34 slow slip events within the Cascadia subduction zone, 1997-2005.” J. Geophys. Res., 113(B4), B04404.

USACE (U.S. Army Corps of Engineers). (2012). "Howard Hanson damfact sheet-U.S. Army Corps of Engineers." $\langle$ http://www.nws.usace .army.mil/Media/FactSheets/FactSheetArticleView/tabid/2444/Article /483489/fact-sheet-howard-hanson-dam.aspx $\rangle$

Williams, S. D. P. (2003). "The effect of coloured noise on the uncertainties of rates estimated from geodetic time series." J. Geod., 76(9), 483-494.

WSDOT (Washington State DOT). (2008) "State Route 520, SR 520 bridge replacement and HOV project: SR 520 toll traffic and revenue technical report (Analysis of the 2007 SR 520 Finance Plan Toll Scenarios)." 〈http://www.wsdot.wa.gov/Projects/SR520Bridge/〉 